\title{
GO: ESPORTE, JOGO, LITERATURA OU CULTURA? Borges, Perec, Xul Solar e Kawabata
}

\author{
GO: SPORT, GAME, LITERATURE OR CULTURE? \\ Borges, Perec, Xul Solar, and Kawabata
}

Jacques Fux*

Unicamp / Fapesp

\begin{abstract}
RESU MO
Este artigo tem como objetivo estudar as referências e as relações do jogo de GO encontradas nas obras de Jorge Luis Borges, Georges Perec, Alejandro Xul Solar e Yasunari Kawabata. Considerado um dos mais antigos e mais difíceis jogos de todos os tempos, o GO trabalha com combinações matemáticas, esoterismo e beleza artística; motivos pelos quais os escritores e artistas aqui escolhidos o elegeram como suporte ficcional.
\end{abstract}

PALAVRAS - CHAVE

Jogo de GO, Borges, Perec, Xul Solar, Kawabata

\section{INTRODUÇÃO}

Ao escrever sobre a famosa partida de GO realizada em 1938 envolvendo o mestre invencível Shusai contra o desafiante Minoru Kitanu (Otake), o Prêmio Nobel de 1968, Yasunari Kawabata, não narrou apenas um jogo. Kawabata, na voz de seu narrador Uragami, descreveu minuciosamente a paixão, a devoção, o mistério e a arte que envolve esse fascinante mundo oriental do GO. Ao ver um simples tabuleiro repleto de peças brancas e pretas colocadas por grandes mestres, não estaríamos diante de um simples jogo, mas contemplando uma obra de arte perfeitamente harmônica: "se ambos os jogadores, com grande habilidade, jogarem o melhor possível até o fim do jogo, o tabuleiro ficará coberto com pedras pretas e brancas em perfeita harmonia. Tal jogo é comparável a um excelente trabalho de arte, além do resultado de vitória ou derrota." ${ }^{1}$

Ao discutir e estudar a questão do jogo em várias instâncias da sociedade, Roger Caillois define que

\footnotetext{
*jacfux@gmail.com

${ }^{1}$ KIIN. GO. O jogo mais fascinante do mundo, p. 10.
} 
os jogos de competição conduzem ao desporto, os jogos de imitação e de ilusão prefiguram as religiões do espetáculo. Os jogos de azar e de combinação estiveram na origem de vários desenvolvimentos das matemáticas, do cálculo de probabilidades à topologia. ${ }^{2}$

Segundoele, na categoria dos jogos de competição (agôn), temos alguns esportes (corridas, lutas, futebol) e alguns jogos de tabuleiro (xadrez, damas), diferenciados pelos elementos paidia e ludus. ${ }^{3}$ Assim, o GO, quando estudado sob o viés competitivo, como na partida de 1938, está na categoria de esporte agôn (como o xadrez).

Praticado por japoneses e chineses, o GO pode ser visto como um esporte, jogo, manifestação cultural de uma época e de uma sociedade e como ferramenta ficcional para a literatura, como veremos aqui. Entretanto, para os ocidentais e para muitos leigos, a dificuldade de entender os princípios artísticos e espirituais que envolvem a prática meditativa e contemplativa desse multifacetado jogo é grande, como escreve Marlene Pilarcik:

The Japanese game of GO has a profundity and spiritual depth which are often little understood in the West. For the Japanese, GO has traditionally been more than a contest of skill or endurance - it is a discipline and a creative art that originated in ancient China but developed and flowered in Japan. According to Kawabata, the Japanese "elevated" and "deepened" the game and cultivated its mysteries. ${ }^{4}$

Porém, mesmo diante dessas dificuldades, alguns escritores ocidentais ousaram trabalhar e entender os princípios, o misticismo e as regras desse jogo. Borges, em seu livro A cifra, de 1981, escreveu o poema "O GO", reverenciando seu caráter astrológico, labiríntico e eterno. Esse jogo, talvez inacessível a Borges como ele manifesta em seu poema, foi adaptado por seu grande amigo, o artista Xul Solar, ao desenvolver o "Pan-Ajedrez": um jogo de tabuleiro que mistura xadrez, GO e que "funciona simultaneamente como horóscopo e como dicionário aglutinador de todas as palavras", ${ }^{5}$ remetendo à arte de adivinhação e à mística do GO. Borges e Xul Solar jogaram algumas vezes, e Xul sempre ganhava, pois incorporava novas regras à medida que o tempo e as constelações mudavam.

Outro escritor ocidental que muito se interessou pela arte do GO foi Georges Perec. Com os matemáticos profissionais, poetas e escritores oulipianos Jacques Roubaud e Pierre Lusson, Perec redigiu um tratado de GO com o objetivo de apresentar mais uma de suas muitas restrições literárias ao público francês. Ao apresentar e trabalhar seriamente com a arte milenar do GO, Perec ainda brincou com as possibilidades literárias, linguísticas e recreativas do GO.

Segundo Caillois, os jogos revelam uma forma de pensar e descrever uma determinada época e cultura. Os diferentes tipos de jogos determinam distintas visões e momentos da história humana:

Os jogos podem ser considerados como aspectos do modo de um povo pensar ou entender o mundo e o universo que o cerca. Existe, de facto, uma afinidade, que vai se ampliando,

\footnotetext{
${ }^{2}$ CAILLOIS. Os jogos e os homens: a máscara e a vertigem, p. 14.

${ }^{3}$ paidia: jogo livre, espontâneo, anárquico. ludus: jogo com regras e convenções (CAILLOIS. Os jogose os homens: a máscara e a vertigem, p. 47-50).

${ }^{4}$ PILARCIK. Dialects and change in Kawabata's The master of GO, p. 9.

${ }^{5}$ SCHWARTZ. Xul/Brasil: imaginários em diálogo.
} 
entre as normas do jogo e as qualidades e os defeitos dos membros de uma coletividade. Esses jogos mais preferidos e mais divulgados manifestam, por um lado, as tendências, os gostos, as formas de pensar mais correntes e, simultaneamente, educam e treinam os jogadores nessas mesmas virtudes e nesses mesmos erros, sancionados neles os hábitos e as preferências. De tal maneira que um jogo que determinado povo prefere pode, por seu turno, servir para definir alguns de seus traços morais e intelectuais, fornecer uma prova de exatidão da sua descrição e contribuir para torná-la mais verídica, ao acentuar os perfis daqueles que se dedicam a esse jogo. ${ }^{6}$

Podemos perceber a relação dos povos orientais com o GO: criado pelos chineses e aclamado pelos japoneses, o GO é ensinado nas escolas e visto como uma forma de desenvolvimento espiritual, lógico e artístico. A partida de 1938, narrada por Kawabata, mostra toda essa sensibilidade e devoção, além de descrever as mudanças culturais e a forma de ensino/aprendizado do GO ao longo da Antiguidade e da modernidade.

A devoção e a admiração pelo GO chama nossa atenção para diversas áreas artísticas. Estamos diante de um jogo/esporte de tabuleiro somente? Contemplamos uma obra de arte que, como as mandalas orientais, mudam com o tempo e ao fim são descartadas, sendo "a vida um fragmento de passagem"? 7 Admiramos um jogo matemático e combinatório que, como nas regras oulipianas, ajudam a aumentar as possibilidades literárias? Neste artigo, portanto, pretende-se discutir e relacionar as inúmeras possibilidades do GO com os autores aqui escolhidos.

\section{O GO e Georges Perec}

As origens e a razão da criação do GO são desconhecidas: alguns acreditam que foi criado para se discutir política e outros como uma forma primitiva de ábaco:

Não podemos dar uma explicação definida da forma original e o almejado objetivo do $\mathrm{GO}$, mas parece certo que primeiramente não foi inventado como um jogo. Uma das versões diz que os governantes chineses usaram-no como meio de política e outra diz que era uma espécie de ábaco primitivo. Existem, entretanto, boas razões para se acreditar que o $\mathrm{GO}$, originariamente, estava ligado à arte de adivinhação. ${ }^{8}$

O GO pode ser visto como um jogo de conquista de territórios, citado por grandes estrategistas, como Napoleão Bonaparte e Sun Tzu, em que duas pessoas posicionam suas peças (181 pretas e 180 brancas) num tabuleiro (que pode ter $9 \times 9,13$ x 13 ou 19 x 19). Utilizando o tabuleiro de 19 x 19, encontramos 361 interseções que, segundo os livros chineses, representam o número de dias do ano. Além disso, podemos dividir o tabuleiro em quatro áreas ou territórios, cada uma delas representando as estações do ano. Essa concepção estaria relacionada à arte da adivinhação, já que segredos e revelações poderiam ser feitos a partir desse tabuleiro.

\footnotetext{
${ }^{6}$ CAILLOIS. Os jogos e os homens: a máscara e a vertigem, p.102.

${ }^{7}$ No original, "Shogai ippen sansui" (KAWABATA. O mestre de GO, p.35).

${ }^{8}$ KIIN. GO. O jogo mais fascinante do mundo, p. 6.
} 
De origem chinesa, o GO é um jogo de guerra em que os jogadores devem conquistar as peças do adversário, tornando-as suas e aumentando seu exército e seu território para, por fim, ganhar a partida:

no Japão e na China, o GO tornou-se muito popular entre os guerreiros, principalmente devido aos seus elementos que conduziam a um método excessivamente conveniente para a investigação da tática militar: por exemplo, o tabuleiro podia ser considerado como um mapa do campo de batalha e as pedras brancas e pretas como soldados arrumados para as operações de guerra. ${ }^{9}$

Conhecido também como "arte da harmonia", o GO possui regras simples e que permitem variações e possibilidades matematicamente enormes. Diante de um tabuleiro de 361 interseções, o primeiro jogador pode colocar a peça em qualquer um desses lugares. O outro jogador pode, portanto, colocar sua peça em qualquer uma das 360 interseções restantes. Temos, então, um cálculo matemático de possibilidades chamado fatorial, que resultaria em um número muito maior que o de partículas existentes em todo universo. ${ }^{10}$

Combinações matemáticas, inúmeras possibilidades de leitura e escrita, dinâmica e desafio são algumas das muitas qualidades desse jogo/arte intelectual. Talvez seja por isso que Georges Perec tenha se interessado pelo GO: partindo de regras ou postulados simples, podemos chegar a possibilidades infinitas em tempo humano. ${ }^{11}$ Admirador da literatura a partir de restrições, Perec, juntamente com os matemáticos Jacques Roubaud e Pierre Lusson, após terminar de escrever o lipogramático La disparition, escreveu o livro Le petit traité invitant à l'art subtil du GO, o primeiro manual francês sobre esse jogo, a respeito do qual afirma:

Vers 1965, un professeur de mathématiques, Chevalley, a appris à jouer à mon ami Jacques Roubaud. À son tour, Roubaud a appris le jeu à deux personnes: Pierre Lusson et moi. Et tous les trois, nous avons écrit un livre sur le GO, sans savoir qu'un autre joueur, Girault, connaissait le jeu depuis longtemps et avait rédigé un traité qu'il n'arrivait pas à faire publier. Ensuite, nous avons fondé un club, et tous les membres du club sont devenus assez rapidement plus forts que nous. ${ }^{12}$

Perec, como um corredor de obstáculos, sempre funcionou melhor (ou teve sua imaginação inspirada) quando esteve diante de restrições (contraintes), como escreveu Italo Calvino:

\footnotetext{
${ }^{9}$ KIIN. GO. O jogo mais fascinante do mundo, p. 7.

${ }^{10} \mathrm{O}$ número exato é representado por 360!, o que dá, aproximadamente, 3,98 x 10795. Esse número de possibilidades é muito maior que as combinações possíveis em uma partida de xadrez, por exemplo. Por isso, a grande dificuldade de fazer um software capaz de ganhar de um mestre do GO. Em Literatura e matemática: Jorge Luis Borges, Georges Perec e o OULIPO, há um cálculo do tamanho da Biblioteca de Babel de Borges, mostrando como trabalhar e entender números extremamente grandes, mas que não são infinitos.

${ }^{11}$ Como mostrado, não é infinito o número de possibilidades. Entretanto, em tempo humano, nunca conseguiremos observar todas as possibilidades matemáticas do jogo.

${ }^{12}$ PEREC. Perec entretiens et conférences II, p. 113.
} 
Il y a des coureurs à pied que l'on appelle des sprinters, qui sont très, très bons quand ils courent en ligne droite sur cent mètres: il y en a d'autres qui sont meilleurs quand, sur la piste, ils mettent des obstacles, c'est ce qu'on appelle les coureurs de haies $-110 \mathrm{~m}$ haies, $400 \mathrm{~m}$ haies, etc. Et, en fait, l'Oulipien fait un peu la chose suivante... c'est que pour arriver à saisir ce qu'il veut, il va commencer par mettre un certain nombre d'obstacles sur le chemin qui va le conduire à ce qu'il cherche, et ces obstacles, il va les appeler des contraintes, disons des règles. ${ }^{13}$

Em Le petit traité invitant à l'art subtil du GO, Roubaud ficou responsável pela parte técnica do jogo e por sua contextualização japonesa; Lusson apresentou algumas estratégias e outras técnicas específicas; e Perec contribuiu - bem ao seu estilo - através de brincadeiras, trocadilhos e divertimentos relacionados ao GO. Os capítulos 1 e 2 explicam detalhadamente as regras e as táticas do GO. Logo após essas definições, Perec escreve o capítulo 3, "Saturation", no qual, partindo de seus conhecimentos, produz sua literatura potencial e lúdica, como nos exemplos abaixo:

Quelques joueurs légendaires: Tous les GOchistes. Aphorismes: Au GO, chacun est à la fois le soldat, le commandant de compagnie et le général en chef. Le jeux de mots du type GO-x. L'art du joueur trop nerveux c'est le GO-tic. ${ }^{14}$

Os jogos são tratados de forma séria por Perec, como escreve um dos seus biógrafos, David Bellos:

Le petit traité invitant à l'art subtil du GO met en avant cette idée, que dut être celle de Roubaud avant de devenir aussi celle de Perec, qu'une seule autre activité humaine souffrait la comparaison avec ce jeu; et cette activité n'était pas les échecs, la bête noire du livre, mais... l'écriture. Par quoi il ne fallait pas entendre que l'écriture était un jeu, mais bien que le GO était une activité sérieuse. ${ }^{15}$

No seu célebre livro, A vida modo de usar, Perec faz uma ligação entre a arte da escritura e da literatura e a posição do autor e do leitor em relação à arte do GO:

Há algo de comum entre a arte do puzzle e a arte do GO; só quando reunidas as peças assumirão um caráter legível, adquirirão sentido; considerada isoladamente, a peça de puzzle não quer dizer nada; não passa de pergunta impossível, desafio opaco; mas basta que se consiga conectar uma delas às suas vizinhas, ao cabo de alguns minutos de tentativas e fracassos, ou numa fração de segundo prodigiosamente inspirada, para que a peça desapareça, deixe de existir enquanto tal. ${ }^{16}$

Assim como a arte do puzzle e do GO, a literatura, de acordo com Perec, é feita através da arte combinatória. $\mathrm{O}$ autor, assim como o construtor de puzzles e os jogadores de $\mathrm{GO}$, molda, a partir de regras explícitas (como no caso do oulipianos) e regras linguísticas (em geral), a forma como o texto/jogo será feito. A recepção dessas obras de arte, entretanto, por mais meticuloso que seja o construtor, está completamente fora de alcance.

\footnotetext{
${ }^{13}$ CALVINO citado por PEREC. Perec entretiens et conférences II, p. 309.

${ }^{14}$ LUSSON; PEREC; ROUBAUD. Petit traité invitant à la découverte de l'art subtil du GO, p. 125-135.

${ }^{15}$ BELLOS. Georges Perec: une vie dans les mots, p. 429.

${ }^{16}$ PEREC. A vida modo de usar, p. 13.
} 
Perec sempre trabalhou com as potencialidades combinatórias da escrita, relacionando-a com algoritmos computacionais. Um dos problemas da ciência da computação foi a construção de um software ou um algoritmo que jogasse xadrez e que fosse capaz de ganhar de um grande mestre. Em 1997, o computador Deep Blue jogou de igual para igual com o campeão mundial de xadrez Kasparov, realizando, assim, um grande passo na evolução dos algoritmos e estruturas para o xadrez. Em 1998, realizou-se uma partida de GO na Associação Americana de Inteligência Artificial entre o computador Hardtalk e Janice Kim, 27 anos e jogadora profissional de GO. Mesmo com um handicap de 25 pedras para o computador, Kim ganhou facilmente o jogo, mostrando a dificuldade de projetar um programa para bater um mestre, ainda que jovem, do GO. ${ }^{17}$

Perec explica a dificuldade do jogo em relação ao xadrez:

Peut-être parce que c'est un jeu vraiment difficile. Et un peu aride. En outre, il n'a pas bénéficié, comme les échecs, d'une sorte de tradition: en France, des rubriques d'échecs paraissent régulièrement dans les journaux. Mais aussi, dans le jeu d'échecs, on poursuit un but unique: la prise du Roi, et il n'y a que trois solutions: on gagne, on perd, ou on fait nul. Le GO, au contraire, est un jeu continu, et qui fait appel à des dispositions d'esprit très différentes. Tenez: un des principaux écueils à la compréhension du GO, c'est de savoir quand la partie est terminée, à quel moment l'un des deux joueurs contrôle plus de territoire que l'autre, et comment se matérialise cet avantage! Quand on lit, dans des comptes rendus de parties de GO, que quelqu'un abandonne au $60^{\mathrm{e}}$ ou au $90^{\mathrm{e}}$ coup, parce qu'il sait qu'il perdra finalement de deux points, on se dit que ce n'est pas possible! Et pourtant, la plupart du temps, les différences, en tout cas entre joueurs de même niveau, ne sont pas plus importantes. Tout de même, depuis cette époque, il y a eu un Français champion d'Europe. ${ }^{18}$

Assim, diante de todas as possibilidades artísticas, matemáticas e históricas que o GO permite, entendemos a citação de Perec, relacionando a literatura ao GO: "Il n'existe qu'une seule activité à laquelle se puisse raisonnablement comparer le GO. On aura compris que c'est l'écriture." ${ }^{19}$

\section{O GO em Xul Solar e Borges}

De um lado, encontramos o mecanicismo combinatório de Perec, ao trabalhar com as possibilidades matemáticas e lúdicas do GO. Porém, de outro, encontramos a inspiração poética, astrológica e mística de Borges e Xul Solar. Em seu poema "O GO", Borges vislumbra outras possibilidades, além das descritas por Perec e pelos oulipianos:

Hoje, nove de setembro de 1978, tive na palma da mão um pequeno disco dos trezentos e sessenta e um que se requerem para o jogo astrológico do go, esse outro xadrez do Oriente. É mais antigo que a mais antiga escrita

\footnotetext{
${ }^{17}$ SILVA. Uma breve história do jogo GO: das suas origens ao século XXI, p. 15.

${ }^{18}$ PEREC. Perec entretiens et conférences II, p. 114.

${ }^{19}$ LUSSON; PEREC; ROUBAUD. Petit traité invitant à la découverte de l'art subtil du GO, p. 41.
} 
e o tabuleiro é um mapa do universo.

Suas variações negras e brancas esgotarão o tempo.

Nele podem se perder os homens como no amor e no dia.

Hoje, nove de setembro de 1978,

eu, que desconheço tantas coisas,

sei que agora ignoro mais uma,

e agradeço a meus numes

esta revelação de um labirinto

que nunca será meu. ${ }^{20}$

Mais um dos muitos labirintos de Borges foi descoberto por ele em 1978. Um labirinto com regras simples, mas que simboliza o mapa do universo. A mais antiga das mais antigas escritas parcialmente acessível a um escritor en las orillas, de acordo com Beatriz Sarlo, que "se interrogó, como nadie, sobre la forma de la literatura en una das orillas de Occidente". ${ }^{21}$

Talvez, por trabalhar às margens da literatura, mas sendo ao mesmo tempo cosmopolita e universal, ${ }^{22}$ Borges tenha tido acesso ao labirinto da cultura japonesa/chinesa do GO possivelmente por intermédio de seu nume, Alejandro Xul Solar. Assim escreve Borges sobre um de seus amigos esenciales em "Recuerdos de mi amigo Xul Solar":

Me parece estar viendo a ese hombre alto, rubio y evidentemente feliz. Creo que uno puede simular muchas cosas, pero nadie puede simular la felicidad. En Xul Solar se sentía la felicidad: la felicidad del trabajo y, sobre todo, de la continua invención. ${ }^{23}$

Xul vivia recriando o Universo. Artista, foi responsável pela criação de algumas linguagens e também de um jogo de xadrez/GO muito interessante e diferente, que jogava frequentemente com Borges. Suas obras estão carregadas de complexos simbolismos, como ele mesmo afirma:

Soy el creador de una lengua para la América latina: el neo criollo con palabras, sílabas, raíces de las dos lenguas dominantes: el castellano y el portugués. Soy el creador de un idioma universal: la panlengua, sobre las bases numéricas y astrológicas, que contribuirá a que los pueblos se conozcan mejor. ${ }^{24}$

Em Buenos Aires, na rua Laprida, encontra-se o Museu Xul Solar. Lá estão expostos muitos quadros com referências numéricas, cabalísticas e esotéricas, além de serem apresentadas novas linguagens artificiais criptografadas por Xul e que foram decifradas por Borges. Estão também no Museu alguns de seus trabalhos mais curiosos: um piano multicolor com um teclado de três fileiras, páginas com figuras e sinais de um novo sistema de notação musical, 24 cartas de um Tarô desenhadas numa cartolina, máscaras de personagens de um teatro de fantoches que representam os signos do Zodíaco e, para terminar, o mais intrigante e esotérico jogo de xadrez/GO. Chamado de "Pan-ajedrez, Pan-juego ou Ajedrez Criollo", assim o jogo é descrito por Xul:

\footnotetext{
${ }^{20}$ BORGES. O GO, p. 370.

${ }^{21}$ SARLO. Borges, un escritor en las orillas, p. 16.

${ }^{22}$ SARLO. Borges, un escritor en las orillas.

${ }^{23}$ BORGES citado por CAMURATI. Los "raros" de Borges, p. 259.

${ }^{24}$ XUL SOLAR citado por PELLEGRINI. Xul Solar, p. 26-27.
} 
Un juego de habilidad combinatoria, Independiente del azar, para una nuestra civilización más perfecta en lo intelectual, científico y estético, que ha de crear en esta paz, cuyo primer día hábil es hoy. El motivo y la utilidad, digamos también lo único de este nuevo juego, está en que reúne en sí varios medios de expresión completos, es decir, lenguajes, en varios campos que se corresponden sobre una misma base, que es el zodíaco, los planetas y la numeración duodecimal. Esto hace que coincidan la fonética de un idioma construido sobre las dos polaridades, la negativa, la positiva y su término medio neutro, con las notas, acordes y timbres de una música libre y con los elementos lineales básicos de una plástica abstracta, que además son escrituras. También coinciden los escaques, como grados del círculo, con el movimiento diurno y anual del cielo, el tiempo histórico y su drama expresado en los astros..$^{25}$

Nessa passagem, Xul enfatiza uma série de correspondências de seu xadrez/GO com outros conceitos: o zodíaco, o sistema de numeração duodecimal, um idioma bipolar com os acordes de uma música livre e a relação entre as casas do tabuleiro com o drama humano do tempo histórico. Seu intuito é mostrar a concepção esotérica da unidade do cosmos e da harmonia universal, a oculta correspondência entre linguagem, música, pintura, jogos, literatura, matemática, arquitetura e a vida; a aspiração romântica de uma obra de arte total. Difícil de ser entendido e jogado, esse Pan-juego resume o pensamento e a prática artística de Xul Solar, que continua assim a descrever o funcionamento e a complexidade do seu jogo:

Un escaque corresponde a 10 minutos de tiempo en el día, 2 grados y medio de arco (o más o menos un día en el año), una nota musical (grado de la escala), un sonido vocálico simple o compuesto, un número de orden, un producto en la tabla pitagórica de multiplicación, en sistema duodecimal (el más perfecto), etc. Como cada pieza se distingue por una consonante (salvo los peones iguales a números), resulta que cada distinta posición en los escaques que están marcados con vocales o combinaciones de éstas, siempre diferentes, produce palabras muy diversas, por cientos de miles, y con varias piezas juntas por muchos millones; quiere decir que el fundamento de este juego es un diccionario de una lengua filosófica a priori, que si se escribe con los signos elementales correspondientes a sus sonidos - especie de taquigrafía triple de líneas, formas y gestos, que se describe en otra ocasión - forma toda clase de dibujos (abstractos) y combinaciones musicales, también ínsitas en las distintas posiciones de la marcha del juego. ${ }^{26}$

Aqui podemos entender seu xadrez/GO como um conjunto de relações, interrelações, conexões matemáticas, musicais, filosóficas, esotéricas e algorítmicas, além de fazer referência ao sistema duodecimal, que, em sua opinião, é o melhor de todos. Sobre o sistema e trabalho de seu amigo, Borges escreve:

Hace más de doce años que Xul Solar predica (vanamente) el sistema duodecimal de numeración; más de doce años que todos los matemáticos de Buenos Aires le repiten que ya lo conocen, que jamás ha oído un dislate igual, que es un utopía, que es una mera practicidad, que es impracticable, que nadie escribe así, etc. Quizá este libro (que no es obra de un mero argentino) anule o atempere su negación. Pero a medida que lo explicaba, comprendía que su pensamiento ya había dejado atrás lo que explicaba, es decir que al explicar iba enriqueciéndolo y por eso creo que nunca llegué a entenderlo, porque él mismo se daba cuenta de que lo él decía ya era anticuado y agregaba otra cosa. ${ }^{27}$

\footnotetext{
${ }^{25}$ XUL SOLAR citado por CAMURATI. Los "raros" de Borges, p. 292.

${ }^{26}$ SOLAR citado por CAMURATI. Los "raros" de Borges, p. 294.

${ }^{27}$ BORGES. Jorge Luis Borges em "Sur", 1931-1980, p. 216.
} 
O tabuleiro do xadrez de Xul está dividido em 12 filas horizontais e 13 filas verticais, com 156 casas, mas há também uma versão com um tabuleiro de 169 casas (13x13), como no caso do GO.

Algumas diferenças podem ser traçadas entre o xadrez/GO de Xul e as referências de Borges, tanto ao xadrez quanto ao GO. No poema "Xadrez", Borges descreve os movimentos das peças de forma sucinta, simples, porém utiliza todo seu simbolismo através das frequentes referências literárias (no caso, a Omar Khayyan), a Deus e a seus jogos de espelho e labirintos. Xul, ao contrário, apresenta um jogo complexo, em que cada peça apresenta uma função e uma relação diferentes e que, também, está em constante mutação:

Em seu austero canto, os jogadores
Regem as lentas peças. O tabuleiro
Os demora até o alvorecer nesse severo
Espaço em que se odeiam duas cores.

Lá dentro irradiam mágicos rigores

As formas: torre homérica, ligeiro

Cavalo, armada rainha, rei postreiro,

Oblíquo bispo e peões agressores.

Quando os jogadores tiverem ido, Quando o tempo os tiver consumido, Certamente não terá cessado o rito.

No Oriente, acendeu-se esta guerra Cujo anfiteatro é hoje toda a terra. Como o outro, este jogo infinito.

Tênue rei, oblíquo bispo, encarniçada Rainha, peão ladino e torre a prumo Sobre o preto e o branco de seu rumo Procuram e travam sua batalha armada.

Não sabem que a mão assinalada

Do jogador governa seu destino, Não sabem que um rigor adamantino Sujeita seu arbítrio e sua jornada.

Também o jogador é prisioneiro (A máxima é de Omar) de um tabuleiro De negras noites e de brancos dias.

Deus move o jogador, e este, a peça.

Que deus detrás de Deus o ardil começa

De pó e tempo e sonho e agonias? ${ }^{28}$

Místicas e envolventes, as referências ao GO e ao xadrez em Borges e Xul Solar redescobrem e reinventam as possibilidades culturais e artísticas do GO visto no Oriente. Como dito, o GO pode ter sido inventado como forma de arte de adivinhação, recurso poético utilizado tanto por Borges quanto por Xul Solar.

${ }^{28}$ BORGES. Xadrez, p. 211-212. 


\section{Kawabata, GO e a literatura}

A visão combinatória de Perec e a posição labiríntica e mística de Borges e Xul Solar em relação ao GO foram devidamente discutidas. Resta, todavia, compará-las com a visão in loco do escritor japonês Yasunari Kawabata.

No livro O mestre de GO, Yasunari Kawabata tenta mostrar e resgatar a mágica e a mística que existe nos devotos do GO, sobretudo nos japoneses: "o GO japonês é considerado uma arte, ultrapassando a concepção do chamado play ou game. Há nele um fluxo da antiga tradição do Oriente, imbuída de mistério e de nobreza espiritual."29

A profundidade mística e artística do GO japonês nos remete novamente a Xul Solar e Borges, de acordo com as palavras do narrador Uragami:

Foi através dos japoneses que o GO se tornou uma arte elevada e de profundidade espiritual. (...) Não obstante, foram os japoneses que exploraram a profundidade dessa sabedoria, que os chineses acreditaram ser uma diversão dos eremitas, a qual encerra haustos divinos, e seus mais de 360 caminhos contêm os princípios da Natureza, do Universo e da vida humana. ${ }^{30}$

O GO, com seus mistérios e estratégias, costuma ganhar destaque em épocas de guerra, de acordo com Uragami:

o GO costumava ganhar popularidade em tempos de guerra, que houve muitos guerreiros que jogavam $\mathrm{GO}$ em seu acampamento guerra, e que a arte marcial japonesa se harmoniza com o espírito do Caminho da Arte e se assemelha ao caráter religioso de uma pessoa. $\mathrm{O}$ GO simboliza bem essas peculiaridades. ${ }^{31}$

Porém, além de estratégico, o GO é arte, música, criação literária: "o mestre vinha tratando esta partida como a criação de uma obra de arte. (...) Também no GO há criação e processos criativos nos dois jogadores; (...) há fluxo de corações e harmonia como na música." ${ }^{2}$

Ao narrar a última partida do então invencível mestre e artista Shusai contra o novo e talentoso Otake, o narrador Uragami, repórter desse importante encontro, transmite a seus leitores todo o sofrimento e toda plasticidade do jogo ao longo das suas 237 jogadas e quase seis meses de duração.

Shusai, até então devoto da arte do GO, corrompe-se aceitando jogar a sua última partida por uma quantia grande de dinheiro. O livro mostra a grande repercussão que esse evento causou na sociedade japonesa, nos jornais e na saúde dos jogadores. Tomando a definição de Huizinga para jogo, e sua concepção idealizada, percebemos que Kawabata constrói uma narrativa mostrando que o GO é muito mais que um jogo, mas que, com o passar das gerações, foi perdendo seus valores artísticos e místicos.

\footnotetext{
${ }^{29}$ KAWABATA. O mestre de GO, p. 142.

${ }^{30}$ KAWABATA. O mestre de GO, p. 143.

${ }^{31}$ KAWABATA. O mestre de GO, p. 147.

${ }^{32}$ KAWABATA. O mestre de GO, p. 195.
} 
Sob o ponto de vista da forma, pode resumidamente, definir-se jogo como uma acção livre, vivida como fictícia e situada para além da vida corrente, capaz, contudo, de absorver completamente o jogador, uma acção destituída de todo e qualquer interesse material e de toda e qualquer utilidade; que se realiza num tempo e num espaço expressamente circunscritos, decorrendo ordenadamente e segundo regras dadas e suscitando relações grupais que ora se rodeiam propositadamente de mistério ora acentuam, pela simulação, a sua estranheza em relação ao mundo habitual. ${ }^{33}$

Kawabata mostra lentamente a disputa entre o passado, na figura de Shusai, preso às reminiscências de um tempo artístico e glorioso do GO, contra a modernidade, na figura de Otake, destemido, audaz e prepotente que usa de todas as técnicas, regras e lógica em busca, não mais da contemplação artística do GO, mas do sucesso e da glória pessoal. Assim escreve Pilarcik:

The master of GO, one of Kawabata's most elegiac novels, captures the poignantly beautiful fading of an era as Japan enters the modern age. The narrative is based on the 1938 championship GO match between the aging master Shusai and his youthful challenger, Kitani Minoru, known as Otake in the novel. With the defeat and death of the aristocratic master, the paste gives way to the progressive, competitive, and time-obsessed forces of new age; the grace of an elegant tradition succumbs to an unchivalrous modernity; Eastern sensibility feels the thrust of Western scientific rationalism; and ending verges on beginning in a fluid, continually changing universe. ${ }^{34}$

O mestre de GO pode ser lido como uma disputa entre a nostalgia dos tempos artísticos e contemplativos da Antiguidade contra a técnica, a lógica e a busca do sucesso nos tempos modernos. A arte do GO, diante da modernidade, perde a essência, o ludismo e a beleza. Relembrando "A obra de arte na época de sua reprodutibilidade técnica", na qual Walter Benjamin, citando Brecht, escreve: "desde que a obra de arte se torna mercadoria, não mais se lhe pode aplicar a noção de obra de arte"; ${ }^{35}$ podemos pensar, também, nas mudanças e nas novas visões do GO:

The most fundamental level of that conflict is the confrontation of two completely different ways of understanding the nature of human existence at the moment when one is giving way to the other and while both are still vital enough to sustain the conflict's intensity: on the one hand, the traditional Japanese culture's organic view of human beings as emotional and subjective participants in the integrative process of experiencing a complex universe of which they are a functioning element; on the other hand, a systematic view of human beings as objective observers of the universe, categorizing, systematizing, and controlling their experience of a world from which they try to stand apart. ${ }^{36}$

Outra leitura possível desse livro de Kawabata seria compará-lo às tragédias gregas. O mestre Shusai, durante sua última partida, vai perdendo todas suas forças e se assimilando à modernidade. Shusai começa a sofrer a cada jogada, exaurindo-se até morrer após sua única derrota:

\footnotetext{
${ }^{33}$ HUIZINGA citado por CAILLOIS. Os jogos e os homens: a máscara e a vertigem, p. 24.

${ }^{34}$ PILARCIK. Dialects and change in Kawabata's The master of GO, p. 9.

${ }^{35}$ BENJAMIN. A obra de arte na época de sua reprodutibilidade técnica, p. 232.

${ }^{36}$ BOURQUE. Tragic vision in Kawabata's The master of GO, p. 83.
} 
To that extent, Kawabata's novel achieves the scope of Greek tragedy in that both, using different metaphors as vehicles, constitute a fictionalized record of the culture's development from an organic to a systematic self-conception. Aeschylus's Oresteia provides a good parallel. In that trilogy, the dramatic theme revolves around Orestes's dilemma in the face of conflicting demands posed by the blood-vengeance tradition: he must avenge his father, but he must not kill his mother, an act that constitutes the only acceptable form of vengeance. He is finally vindicated in a court of law especially formed for the purpose by Athena, the goddess of wisdom, and the trilogy becomes a symbolic recreation of the Greek culture's historical process of transition from the old mythological beliefs to the more rational systems of civil law. Orestes is the objectification, the symbolic embodiment of that transition. In the same way the GO match in Kawabata's novel is the metaphor for the Japanese culture's transition from the old tradition to the more rational systems of the modern world. In fact, it is to a considerable degree the same tradition in both cultures. Not that the Japanese tradition can be characterized as pre-analytical in the same sense as the Homeric tradition which describes warriors as generations of leaves, but both traditions express a remarkably similar view of what humanity becomes when rationality begins to dominate culture and overshadows whatever organic tradition existed before it. And that vision of humanity is an important element in tragedy. ${ }^{37}$

A disputa entre Otake e Shusai pode ser vista como a reverência à arte e ao passado contra o utilitarismo contemporâneo: "the master is a man of many talents and interests; Otake is a GO player and nothing else. The master appreciates the process of the game as an art." 38 Porém, ao longo da partida, a arte do GO vai se perdendo e se transformando somente em um jogo de tabuleiro, sagrando Otake como vencedor.

\section{CinCO PONTOS FINAIS}

Ao apresentar a composição artística do tabuleiro após as 237 jogadas, o renomado juiz, apenas para confirmar o resultado final, pergunta ao ex-invencível mestre Shusai: "são cinco pontos?" "Sim. Cinco pontos...". ${ }^{39}$ Shusai havia perdido o jogo e sua arte. Porém, como Perec ressaltou acerca da dificuldade do GO, não conseguimos perceber que, de fato, a vitória tenha sido de Otake por cinco pontos; apenas admiramos a bela estrutura de 237 peças pretas e brancas em um tabuleiro de 361 espaços:

Assistir à etapa final desta partida foi como observar uma máquina veloz e de implacável precisão matemática; havia também uma estética de disciplina e organização, o que proporcionava uma agradável sensação. Apesar de se tratar de uma batalha, ela assumia uma bela forma. Crescia a beleza das imagens dos jogadores. ${ }^{40}$

Diante da incompreensão nos fascinamos, como Borges, Perec, Xul Solar e Kawabata, pela beleza e pelas inúmeras possibilidades do GO. Borges, ao referenciar esse labirinto infinito, reverencia o tempo artístico e glorioso do GO, visto como arte e devoção. Xul Solar, ao criar seu Pan-ajedrez, esotérico, místico e linguístico, que trabalha

\footnotetext{
${ }^{37}$ BOURQUE. Tragic vision in Kawabata's The master of GO, p. 87.

${ }^{38}$ BOURQUE. Tragic vision in Kawabata's The master of GO, p. 89.

${ }^{39}$ KAWABATA. O mestre de GO, p. 210.

${ }^{40}$ KAWABATA. O mestre de GO, p. 208.
} 
com letras, números, desenhos, línguas, ainda celebra a antiga e romântica noção do GO como arte da adivinhação. Perec e seus companheiros do OULIPO, já inseridos na contemporaneidade, buscam aplicações e combinações possíveis para se trabalhar restritiva e potencialmente com esse jogo. Além disso, os oulipianos inferem possibilidades de leitura e recepção dessas obras literárias restritivas e contemplativas. Já Kawabata, através de seu narrador Uragami, conta todas essas histórias literárias, entrelaçando as visões e concepções de Perec, Borges e Xul Solar.

Assim, podemos constatar que o GO mistura literatura, ficção, esporte, cultura, combinação, matemática, misticismo, esoterismo e adivinhações, mas que ainda merece muitos outros estudos contemplativos no mundo ocidental.

A)

\begin{abstract}
A B STRACT
This article studies the references and the relations between the game of $\mathrm{GO}$ and the works of Jorge Luis Borges, Georges Perec, Alejandro Xul Solar and Ysunari Kawabata. Considered one of the most ancient and difficult games ever known, GO deals with mathematical combinations, esotericism and artistic beauty - very good reasons for the writers and artists studied in this paper to choose it.
\end{abstract}

\title{
KEYWORDS
}

Game of GO, Borges, Perec, Xul Solar, Kawabata

\section{REFERÊNCIAS}

BELLOS, David. Georges Perec: une vie dans les mots. Paris: Seuil, 1994.

BENJAMIN, Walter. A obra de arte na época de sua reprodutibilidade técnica. In: ADORNO et al. Teoria da cultura de massa. Trad. Carlos Nelson Coutinho. São Paulo: Paz e Terra, 2000. p. 221-254.

BORGES, Jorge Luis. Xadrez. In: BORGES, Jorge Luis. Obras completas II. Trad. Josely Vianna Baptista. São Paulo: Globo, 1999a. p. 211-212.

BORGES, Jorge Luis. O GO. In: BORGES, Jorge Luis. Obras completas III. Trad. Josely Vianna Baptista. São Paulo: Editora Globo, 1999b. p. 370.

BORGES, Jorge Luis. Jorge Luis Borges en "Sur", 1931-1980. Buenos Aires: Emecé, 1999c.

BOURQUE, Joseph H. Tragic vision in Kawabata's The master of GO. Rocky Mountain Review of Language and Literature, v. 36, n. 2, p. 83-94, 1982.

CAILlOIS, Roger. Os jogos e os homens: a máscara e a vertigem. Trad. José Garcez Palha. Lisboa: Cotavia, 1990.

CAMURATI, Mireya. Los "raros" de Borges. Buenos Aires: Corregidor, 2006.

KAWABATA, Yasunari. O mestre de GO. Trad. Meiko Shimon. São Paulo: Estação Liberdade, 2011. 
KIIN, Nihon. GO. O jogo mais fascinante do mundo. Trad. Susy Catta-Preta e Osamu Kikkawa. Tokyo: Sokosha, 1974. V. 1: Introdução.

KIIN, Nihon. GO: the world's most fascinating game. Tokyo: Koho, 2003.

LUSSON, Pierre; PEREC, Georges; ROUBAUD, Jacques. Petit traité invitant à la découverte de l'art subtil du GO. Paris: Christian Bourgois Éditeur, 2003.

PADOVANO, S. Petit traite du jeu de GO. Paris: La Pensée Sauvage, 1971.

PEREC, Georges. A vida modo de usar. Trad. Ivo Barroso. São Paulo: Companhia das Letras, 1991.

PEREC, Georges. Perec entretiens et conférences I. Paris: Joseph K./Centre National du Livre, 2003a.

PEREC, Georges. Perec entretiens et conférences II. Paris: Éditions Joseph K./Centre National du Livre, 2003b.

PELLEGRINI, Aldo. Xul Solar. In: CATÁlOGO MUSEU XUL SOLAR. Buenos Aires: Fundación Pan Klub, 1990, p. 28.

PILARCIK, Marlene A. Dialects and change in Kawabata's The master of GO. Modern Language Studies, v. 16, n. 4, p. 9-21, Autumn 1986.

SARLO, Beatriz. Borges, un escritor en las orillas. Buenos Aires: Seix Barral, 2007.

SILVA, Alexandre Pinheiro. Uma breve história do jogo GO: das suas origens ao século XXI. Monografia. Brasília: Ed. UnB, 2011.

SCHWARTZ, Jorge. Xul/Brasil: imaginários em diálogo. Revista do Instituto de Estudos Brasileiros, n. 53, Set 2011. Disponível em: <http://www.revistasusp.sibi.usp.br/ scielo.php?pid=S0020-38742011000200004\&script=sci_arttext $>$. Acesso em: 12 set. 2012 